\title{
Alternative tree species on farms
}

J.D. HOCKING

Parewanui Road, RD 1, Bulls

jdhocking@xtra.co.nz

\begin{abstract}
The more commonly and successfully grown species of timber trees, grown in New Zealand as alternatives to radiata pine, are briefly reviewed, with emphasis on site requirements and timber end uses. Their silviculture and marketing is considered. The groups covered are Douglas Fir (Pseudotsuga menzesii), the cypresses (Cupressus species and hybrids), eucalypts (Eucalyptus spp.), acacias (Acacia melanoxylon and some others) and more briefly redwood (Sequoia sempervirens and Sequoiadendron giganteum) and poplars (Populus spp.).
\end{abstract}

\section{Introduction}

This paper concentrates on alternative tree species to radiata pine (Pinus radiata) for timber production, with little emphasis on the numerous other roles that trees can play on farms. However, even when just considering timber possibilities, New Zealand growers are faced with a plethora of possibilities. Probably no other country can grow as many potential timber species as well as we can in New Zealand, so it is ironic that we have the most narrowly-based forestry industry in the world, with over $90 \%$ of our production and marginally under $90 \%$ of the forest area, being radiata pine.

This narrow focus reflects the ease of establishing, growing and processing radiata pine, its broad site tolerance, the all-round versatility of its timber, the short, 20-30 year harvesting rotation and, not least, over a hundred years of experience and research. If we are prepared to look at more site-specific and longer rotation species, there is a myriad of possible species, many with superior wood properties to radiata pine.

In considering possible species I would emphasise the following requirements:

- Inherently good wood properties, including ease of processing, stability, good working properties, amenity, strength, hardness, durability or other special properties. You should be looking for wood properties complementary, rather than comparable with, radiata pine. Specialised uses, e.g. stiffer eucalypt timber used in laminated veneer lumber, may be significant but these are often limited markets.

- Tree form needs to be adequate for easily milled logs.

- Reliable, established markets are reassuring, but remember that trees planted today will not be harvested for 20 to 40 years, and conditions could change 
markedly. Detailed forecasts are bound to be wrong, and "broader brush" predictions are still uncertain.

- Any species needs good growth rates and productivity.

- It needs adequate site tolerance and site availability (soils, temperatures, rainfall, shelter, etc.), to be grown on some scale. Ideally, it should be able to grow on sites unsuited for radiata pine.

- The silviculture should be understood at least in principle, and ideally preferred regimes established.

- There should be no major tree health or pest problems.

- The amenity values of any species can be important in a farm forestry situation.

- A substantial, ongoing research programme is desirable prior to any larger scale investment in a species.

When considering alternative specie, we must recognise that the information available for growers is limited by comparison with that available for radiata pine, where we have growth models and predictions for recoverable volumes and log grades. This level of understanding is not available for the alternatives, though some are better understood than others.

Please note that I am emphasising trees grown for solid wood, rather than for processing into fibre products, such as pulp, paper or fibreboard. Heavily processed wood products return little or nothing to the grower unless you are adjacent to a mill. New Zealand does not have the low opportunity value, low logging cost, land suitable for pulp wood forestry, and pulp logs are a waste product of our forests.

Several groups of tree species score reasonably well in these assessments, but I will consider only the four best-known groups in more detail and briefly mention a few more.

\section{Douglas fir (Pseudotsuga menziesii)}

Douglas fir is hardly an alternative, being New Zealand's number two plantation species, with close to $6 \%$ of the plantation estate and increasing. It is primarily a structural timber, but is well known and highly rated internationally, especially around the Pacific basin. The provenances currently available in New Zealand generally require higher altitude (over $500 \mathrm{~m}$ in the North Island), cooler sites with reliable rainfall, especially summer rainfall, in the range $1000-1500 \mathrm{~mm}$ p.a.. Sites need to have good drainage for water and cold air, late frosts can be a problem, and this normally means slopes rather than flats. It will grow well on many sites where radiata pine is restricted by snow or wind. Swiss needle cast disease (Phaeocryptopus gaeumannii) is one of the limiting factors in the North Island, but there are more southern, low altitude provenances from California that may make Douglas fir a viable option over more of the North Island. 
Being a structural timber, pruning is not a priority for Douglas fir and small diameter logs are quite acceptable, provided they are straight. Consequently, high, final crop stocking rates of 500-600 stems/ha (sph) are favoured for maximum volumes/ ha. Preferred rotation length used to be around 60 years, but current suggestions are to aim at 35-40 years with the possibility of production thinning in the mid'20s. Establishment needs care as the roots must not be allowed to dry and good weed control is necessary.

In the early 1990s there were claims that a Douglas fir stand at Lake Ohau was the most valuable plantation in the world, worth $\$ 250,000$ per ha at 50 years. Forest Research manages a Douglas Fir Management Co-operative, which undertakes a wide ranch of research projects relevant to growing Douglas fir in New Zealand. Membership is by subscription.

\section{Cypresses}

This group of species and hybrid clones offers timbers that are very similar, with excellent working and finishing properties, attractive appearance, good durability, adequate strength but limited hardness. They have long been compared with kauri for properties and uses. The timber, mainly from old shelterbelts and a few untended plantations of C. macrocarpa, is already well known and highly regarded on the local market, being used for furniture, joinery, panelling, boat building, structural and general farm uses. Recently, slice veneer for wood panels has emerged as a very high value end use, and top quality pruned cypress logs are currently, (as of mid-2003), worth $\$ 300-400 / \mathrm{m} 3$ on truck, about three times as much as equivalent, pruned, radiata pine logs.

While Cupressus macrocarpa is the best known of the cypresses, cypress canker (caused by the fungi Seridium unicorne and Seridium cardinale) now severely restricts the use of this species and in addition, it can be a poorly formed tree with very heavy branching. However, on cooler, shadier and sheltered sites, the disease is less of a problem, so C. macrocarpa can still be considered for much of the South Island and south facing slopes in the North Island. Forest Research has had a breeding programme underway for some years and there has also been some selection for seed lots and clones that show better health, form and/or vigour. Appropriate matching of clone or seedlot and site can still give satisfactory results. C. macrocarpa requires at least moderate soil fertility and certainly higher soil fertility levels than required by radiata pine.

The other major species is the Mexican cypress (C. lusitanica). Although seedlots and provenances vary considerably, this species is generally less disease prone, has better form than C. macrocarpa, and is to be preferred on warmer sites. There are some claims that the wood is inferior to C. macrocarpa and it often has a much lower proportion of heartwood, but many end users regard the timbers as being 
inter-changeable. I believe that $C$. lusitanica is probably more tolerant of lower fertility sites, e.g. sand dunes, but it is certainly less tolerant of exposure to wind, especially salt-laden coastal winds, and can also be damaged by possums. Forest Research has a limited breeding programme for $C$. lusitanica.

Two groups of hybrid cypresses are also worth considering. The familiar Leyland cypresses are hybrids of C. macrocarpa and Chamaecyparis nootkatensis and have some advantages in site tolerance and health. Oven's cypress, a hybrid of $C$. lusitanica and Ch. nootkatensis, is a tree of good form and health with good site tolerance but $C$. lusitanica's sensitivity to coastal, saline winds. Oven's cypress is a hybrid that deserves wider planting, especially if we can create more selected hybrids to add to the one existing clone. Other crosses are also worth considering - think of the role of hybrids in willow and poplar breeding. On the down side, clonal material is more expensive to propagate than seedlings.

On very dry sites, C. torulosa (Bhutan cypress) is also worth considering.

Talk to the local Farm Forestry Association when deciding on the most appropriate species and provenances for a site.

The cypresses can be established with similar techniques to radiata pine, including the same releasing chemicals. However pruning should be more aggressive down to $5-6 \mathrm{~cm}$. diameter trunks, as recent work has shown there is little growth loss even after pruning to $3-4 \mathrm{~cm}$. trunks. If pruning is delayed it can turn into a formidable task, with numerous, large branches, especially with $C$. macrocarpa and Leyland cypresses.

The cypresses normally outgrow radiata pine for the first 3-4 years then fall behind, especially in height growth, but on good sites they are very productive, with annual volume increments in the range $20-30 \mathrm{~m}^{3} /$ year and final standing volumes well over $1000 \mathrm{~m}^{3} / \mathrm{ha}$. Individual trees can achieve diameter increments of 3-4 cm/ year. Because smaller diameter, younger logs generally mill quite well, (cypresses do not have the problematic juvenile core of radiata pine), cypresses can be harvested at quite young ages, mid 20s, and some have advocated high stocking rates of 500-600 sph and clear felling at 20-25 years. An alternative would be production thinning on accessible sites, and growing on to achieve the premium, large diameter, pruned logs in a 35-40 year rotation. I would favour final stocking rates no higher than $200 \mathrm{sph}$ and perhaps lower. Others will prefer higher stocking rates.

\section{Eucalypts}

This genus has had rather mixed press over the years and for the novice it can be something of a minefield. However, there are some excellent Eucalyptus timber species and if New Zealand is to have a hardwood industry, then these will be the 
key. In this genus of over 800 species, probably $50-100$ could produce utilisable timber in some part of New Zealand, but in reality, no more than 12-15 species are worth serious consideration, and in all cases species must be matched to site and vice versa. They are very site specific.

There are several generic problems with eucalypts, including insect pests and difficulties with milling and drying. However, these can be minimised by appropriate species selection, good silviculture and correct processing. For instance, not all species are seriously affected by insect pests, which show a strong preference for certain subgenera of Eucalyptus. Growth stresses, a natural feature of eucalypts and indeed most hardwoods, can be minimised by selecting better milling species and growing them to larger diameters (over $60 \mathrm{~cm}$.).

While we do not have detailed growth models for eucalypts, we do know which eucalypts are growing well in New Zealand, their site requirements, milling properties, processing requirements and end uses. Technically, we are already producing some superb eucalypt timbers in New Zealand and this should be weighed against future expectations of supply and demand for such timbers.

In considering eucalypts for timber production, there are several species, or groups of species, that deserve attention.

\section{The Stringybarks}

This group of about 24 species has around 6 very good milling species well suited to New Zealand conditions. They are probably first choice for local, solid wood, eucalypt growers and because they all have very similar, blond coloured timbers with excellent milling and processing properties, good stability, strength, hardness and durability, you can select the species best suited to your conditions. However, all of them prefer warmer sites with good drainage, but soil fertility is optional and some are quite frost hardy. There are, at present, few insect pests attacking stringybarks, but they can suffer from root rots on heavy soils and damp sites. The species, in my order of preference, would be:

- E. muelleriana is probably the best milling species of all and has a long history of vigorous growth and reliable saw-milling in New Zealand. Form is sometimes rather poor, with a tendency for double leaders, but better seedlots are available. It is frost tender and is best grown on free draining, north facing slopes throughout much of the North Island and northern South Island. It will stand fairly exposed sites and low fertility soils. The tortoise-shell beetle (Paropsis charybdis) can do minor foliage damage.

- E. pilularis is not strictly a stringybark but has the same timber. It is a large tree and the bread-and-butter species of the east coast, hardwood industry in Australia. Its site requirements are similar to E. muelleriana but it is somewhat more site sensitive in that it has proved more drought sensitive. 
- E. globoidea and E. eugenioides are similar, somewhat smaller trees and less vigorous than the above on most, but not all, sites. They are generally regarded as more site tolerant, including frost tolerance, but this varies with provenance.

- E. laevopinea is a large tree, highly regarded in Australia but, to date, little grown in New Zealand. It appears to offer much greater frost tolerance than the other stringybarks, but still needs well drained sites.

- E. youmanii and E. baxteri are other smaller trees with good or moderate frost tolerance but have been little grown in New Zealand to date.

\section{The Ash Group Eucalypts}

These are species from the higher altitude, moister, cooler areas of south-eastern Australia and have long been popular species in New Zealand. They belong to the same subgenus as the stringybarks, so have relatively few insect pests but several of them are prone to root rots and in some situations, mainly warmer and summer moist areas, leaf spot fungi. Their timber properties are inferior to the stringybarks, being more difficult to saw and dry, less durable and softer (though still much harder than the softwoods). They all have blond or light brown timbers.

In order of preference, the recommended species are:

- E. fastigata has a long and very successful history in New Zealand. It is a large tree, of sometimes variable form, that is frost hardy and tolerates some exposure. It prefers free-draining soils, but on good sites seems capable of achieving significantly higher basal areas and standing volumes than other eucalypts. It has generally milled very well, though the timber would be regarded as inferior to the stringybarks

- E. obliqua is another large ash eucalypt that has a long and successful history in New Zealand, though it's milling properties have not been as reliable as $E$. fastigata. At best a tall tree of good form, it can be quite variable reflecting its wide range and genetic variability in Australia. It is reasonably frost tolerant and probably more tolerant of both wetter and drier sites than other ash eucalypts. It has long been the "bread-and-butter" hardwood of Victoria.

- E. fraxinoides is more commonly seen as a shelterbelt species, partly because it is both wind tolerant and retains its lower branches, but if pruned it can mill quite well. It will not tolerate wet feet and is susceptible to root rots.

- E. regnans and E. delegatensis are other common ash group species but their milling and wood properties are generally inferior to E. fastigata and E. obliqua. E. delegatensis is notably frost hardy, but not planted much now because of problems with root rots and poor wood drying properties.

Eastern Blue Gums

E. saligna and E. botryoides were, until recent years, highly favoured species in New Zealand because of their very attractive, high quality, dark red timbers. 
Unfortunately, they belong to a group that has a large number of insect pests in Australia, and over the last 20 years, five or six of these pests have arrived in New Zealand with rather devastating effects. Growth rates and the general health of the trees have been severely compromised, though few have actually died. At present, these species cannot be recommended, despite their numerous desirable attributes, including their superb timber and tolerance for wetter sites. At this stage we do not have a good, red, hardwood to substitute for these species.

\section{Southern Blue Gums}

This group is better known for its pulp wood species (E. nitens \& E. globulus) than for solid wood, but $E$. nitens is the most widely grown eucalypt in New Zealand, in pulp wood plantations, farms and life-style blocks and does have some possibilities for solid wood end-uses, especially veneer. The key attributes of $E$. nitens are its fast growth rate, wide site tolerance, though it is not drought tolerant, and good form. It is a good shelterbelt species. On the downside are the afore-mentioned rather poor wood properties, susceptibility to many insect pests and serious problems with leaf-spot fungi in warmer, moister areas. In recent years there have been suggestions that E. globulus subsp. maidenii may have the best milling prospects in this group, but although this sub-species is reasonably common in New Zealand, there seems to be little record of it being milled.

\section{Other Eucalypts}

E. microcorys produces perhaps the most valuable timber of all the eucalypts and has been successfully grown on warm sites, basically northern slopes, over much of the North Island. It is slower growing than most of the other eucalypts and most provenances are notably frost tender, but is otherwise quite site tolerant and notably free of insect pests. Many regard it as one of the most attractive eucalypts.

E. maculata (now known as Corymbia maculata by one taxonomic school) is another excellent milling species for warmer sites of moderate fertility.

For the enthusiast there is then a range of less commonly grown species with interesting and useful timbers. It is a "big playpen" and offers growers plenty of fun, but small volumes of these timbers are unlikely to have much commercial value.

\section{Eucalypt Silviculture}

Several general comments can be made about growing and tending eucalypts:

- Species originating in summer-dry areas (basically areas south of about Sydney) will generally perform poorly in summer-wet areas, especially warm, summer wet areas. This can be a problem in Northland and Bay of Plenty.

- Seek advice on the best seedlots for local conditions. 
- Eucalypts can be interplanted with radiata pine, with the eucalypts being planted a year later. This is a cheaper option and the pines can provide insurance, but it does make management more complicated.

- For most species, planting container-grown stock in spring (September/October) is preferable to bare-rooted stock planted in winter.

- Be very careful with releasing sprays, on light soils residual sprays may affect eucalypts.

- Correct double leaders from age 2 or 3 years and clear lift prune from 3 or 4 years.

- Prune in dry weather during the driest period of the year (mid-late summer) to minimise the risk of silver leaf infection (Chondrostereum purpureum).

- Large diameter logs are needed for reliable milling so final stocking rates should be no more than $200 \mathrm{sph}$ and for many species and sites, $100 \mathrm{sph}$ or less. As with all alternative species, before deciding to grow eucalypts, talk with experienced local farm foresters.

\section{The Acacias}

Easily the best known of the timber acacias is Tasmanian blackwood, (Acacia melanoxylon) a superb decorative and furniture timber that has been grown in New Zealand for over 100 years. Unfortunately, only a few of these trees have matched expectations. Blackwood is a difficult species to grow successfully when your aim is to produce millable logs. Its reputation as a premium decorative timber and the limited quantities of top quality timber produced in New Zealand to date have sustained the enthusiasm in this species locally, but I doubt that too many of the growing operations to date would stand detailed, financial analysis. However, when well sited and well managed the data suggest that internal rates of return of $9-11 \%$ are possible.

A. melanoxylon is by nature an under-story species with the ability to break out into a dominant species when given the chance. It is unusual amongst the acacias in being a long-lived, potentially large tree (over $30 \mathrm{~m}$ in height) that prefers moist and fertile sites. It can survive on a wide range of sites but to produce millable logs you need a site that is:

- Reliably moist, but not a stagnant swamp.

- Reasonably fertile.

- Sheltered and, ideally, a site that will draw the young tree up towards the light.

Given a chance, the young tree will go as high as it needs to obtain light and then adopt the form of a cabbage. The skill in growing A. melanoxylon is to get the cabbage on top of a 5 or 6-metre bole. Generally this is done with intensive, annual, form and clear lift pruning using a diameter gauge, followed by timely thinning to develop a large, well-balanced crown capable of growing a $60 \mathrm{~cm}$. diameter trunk. It can be a very useful species for riparian plantings, especially 
in mixtures with indigenous species, though has been known to spread seed downstream.

At present there is an under-supplied demand for blackwood as a rimu substitute to be used in furniture, bench-tops and other decorative uses.

Anyone planning to grow A. melanoxylon would be well advised to obtain a copy of "Blackwood: A Handbook for Growers and End Users" by Ian Nicholas and Ian Brown (Forest Research bulletin 225, available from the Forest Research publications officer, Private Bag 3020, Rotorua).

\section{Other Acacias}

While A. melanoxylon is the best known of the timber acacias, there are several other Acacia species that produce similar, though perhaps somewhat inferior timbers, and grow on generally poorer and drier sites. The biggest problems with Acacia species seem to be their naturally poor form and remarkable reluctance to grow straight. Acacia dealbata would be easily the best alternative, but form and vigour vary with seedlot and despite impressive growth rates, yields of heartwood can be rather low. It will grow well on fairly exposed, dry sites. Locally grown, A. dealbata timber has been used very successfully for furniture and decorative panelling.

Other possibilities include the very vigorous A. falciformis and A. mearnsii, both with generally poor form, A. elata, which can be difficult to handle in the nursery, and the very variable $A$. decurrens and A. sylvestris. A. mearnsii is currently being grown in Northland, on a limited scale, for pulpwood, but it could become a weed in some areas.

\section{Sequoia and Sequoiadendron}

In recent years there has been renewed interest in growing redwood (Sequoia sempervirens) and to a lesser extent, giant sequoia (Sequoiadendron giganteum) for timber with significant local investment by some Californian forestry companies. Redwood was planted quite extensively in the 1920s and 1930s, and performed very well on moist, sheltered sites in the North Island. However the fast growth rates and wide growth rings resulted in timber that was regarded as markedly inferior to the old growth, Californian product. Now that the Californians are being forced to use second crop timber with comparable, wide growth rings, the New Zealand timber suddenly looks more attractive and some people are enthusiastic about prospects for New Zealand, plantation grown redwood.

S. sempervirens is a site specific species, which is probably why the majority of early plantings failed. It needs reasonable shelter and reliable moisture so tends to be a valley bottom species growing particularly well in the higher rainfall, valleys of the western North Island. When well sited it can grow into very spectacular 
trees with very high volumes of timber per hectare. The Long Mile stand at Whakarewarewa is a wonderful example, but by no means the only one.

At present $S$. sempervirens has a limited local market and the current enthusiasm is based on possible export markets, mainly to California. It is an easy species to saw, even at fairly young ages, and is a low density, softwood with good natural durability and stability, but lacking strength and hardness. However, local, mobile sawmillers seem rather unenthusiastic about the species with heartwood rot being a common problem in older trees. It appears the rot fungi gain access through branch stubs.

The giant sequoia or big tree (Sequoiadendron giganteum), is a distinctly different tree, well suited to higher altitude, colder, drier and exposed sites but there are some impressive trees throughout this country. Traditionally, the timber was regarded as inferior to redwood, but it is now recognised that the sheer size of the trees tended to result in the shattering of the trunk when they were felled.

\section{Poplars}

Poplars are another genus of potential timber trees that have their champions. Poplar timbers are light, but generally tough and resilient, non-durable but easily treated with chemical preservatives, subject to stability problems because of tension wood but quite suitable after treatment for gates, rails and other utilitarian uses. They are also devoid of resins and thus free of any taint or taste, hence their use in food sticks and tongue depressants. Poplar is also an excellent packaging timber.

Poplar is a widely used commodity timber in several European and eastern Asian countries, but I doubt whether it will ever be a widely accepted timber in New Zealand, simply because it is competing with an over-supply of lower grade radiata pine that can do all the same jobs. However, it can definitely have a role as an on-farm timber.

\section{Conclusions}

With all these alternative timber species, you are trying to guess markets 20,30 or even 40 years into the future. I don't know anyone who can reliably predict markets even two or three years ahead, so perhaps a more sensible approach is to ask whether you think you or your property will be better off with a resource of one or some of these tree species. I believe that it would be to your advantage, provided that any such resource is of good quality. The world will not run out of wood fibre, but supplies of high quality logs for conversion to solid wood, i.e. for sawing and veneering, are likely to become increasingly tight. I would suggest that the more readily trees can be converted to high quality solid wood and veneer, the more valuable they will be.

When my father planted C. macrocarpa in the 1960s he no doubt heard many of the same arguments we hear today. When I pruned those trees in the 1970s it just 
seemed the logical thing to do. Today my only regret is that we didn't plant many more, as the returns have been excellent.

Finally, let me emphasise that the experts here are your local farm foresters. The New Zealand Farm Forestry Association has action groups covering cypresses, eucalypts, blackwood and redwood. Anyone thinking of growing any of these groups of species would be foolish not to join the New Zealand Farm Forestry Association and the appropriate action group(s).

\section{Further Reading}

The FRI Bulletin No.124 series covers Douglas fir, cypresses, various eucalypts and numerous other species. They are available from the Forest Research Publications Officer, Forest Research, Private Bag 3020, Rotorua.

Trees for the New Zealand Countryside: A Planter's Guide, John and Bunny Mortimer. Available from Taitua Books, P.O. Box 773, Rotorua.

The Cypress Growers Handbook, Stephen Brailsford. Published by Brailsford Forest Management Ltd., R.D.2, Christchurch.

Growing Eucalypt Trees for Milling on New Zealand Farms, Neil Barr. Available from M.E.F. Smith, R.D.1, Palmerston Nth.

Blackwood: A Handbook for Growers and End Users, Ian Nicholas and Ian Brown. Available from the Publications Officer, Forest Research, Private Bag 3020, Rotorua.

Redwood Growers Handbook, Wade Cornell, 247 Forest Hill Road, Henderson 1008, Auckland

New Zealand Timbers Exotic and Indigenous: The Complete Guide, N.C. Clifton. GP Books.

The New Zealand Farm Forestry Association's quarterly magazine The New Zealand Tree Grower and the newsletters of the action groups contain ongoing information about a wide range of timber species. 
